\title{
Why Stay Home? Temporal Association of Pain, Fatigue and Depression with Being at Home
}

\section{Authors: Craig Ravesloot, Bryce Ward, Tannis Hargrove, Jennifer Wong, Nick Livingston, Linda Torma, and Catherine Ipsen}

NOTICE: this is the author's version of a work that was accepted for publication in Disability \& Health Journal. Changes resulting from the publishing process, such as peer review, editing, corrections, structural formatting, and other quality control mechanisms may not be reflected in this document. Changes may have been made to this work since it was submitted for publication. A definitive version was subsequently published in Disability \& Health Journal, [VOL\# 9, ISSUE\# 2, (November 2015)] DOI\# 10.1016/i.dhjo.2015.10.010

Ravesloot, Craig, Bryce Ward, Tannis Hargrove, Jennifer Wong, Nick Livingston, Linda Torma, and Catherine Ipsen. "Why Stay Home? Temporal Association of Pain, Fatigue and Depression with Being at Home." Disability \& Health Journal 9, no. 2 (November 2015).

DOI: 10.1016/j.dhjo.2015.10.010

Made available through Montana State University's ScholarWorks scholarworks.montana.edu 


\title{
Why stay home? Temporal association of pain, fatigue and depression with being at home
}

\author{
Craig Ravesloot ${ }^{\mathrm{a}, *}$, Bryce Ward $^{\mathrm{b}}$, Tannis Hargrove ${ }^{\mathrm{a}}$, Jennifer Wong ${ }^{\mathrm{a}}$, Nick \\ Livingston ${ }^{\mathrm{a}}$, Linda Torma ${ }^{\mathrm{c}}$, and Catherine Ipsen ${ }^{\mathrm{a}}$ \\ a The Rural Institute on Inclusive Communities, USA \\ b The Bureau of Business and Economic Research, USA \\ c Montana State University, School of Nursing, USA
}

\begin{abstract}
Background: Community participation is important to most people with disabilities despite the fact that common secondary conditions like pain, fatigue and depression may increase the difficulty of leaving home. Despite decades of research on these secondary conditions, little is known about how they are associated with being at home.

Objective: We used Ecological Momentary Assessment data to examine within subject fluctuation in these secondary conditions to examine their effect on the likelihood that participants remain at or return home.

Methods: Participants $(n=139)$ were recruited from a population based sampling frame to complete an Ecological Momentary Assessment that queried their location and experience with secondary conditions six times a day for two weeks.

Results: Between subjects secondary condition ratings averaged across time periods indicated that pain and depression were associated with the share of measurement periods that respondents reported being at home. Within subject results indicated that a standard unit increase in pain, fatigue and depression was associated with being home one to two days later. Within day results indicated that increases in pain and fatigue were associated with increased likelihood of being home later, but increases in depression were associated with lower likelihood of being home later.

Conclusion: These results suggest there may be a complicated relationship among these secondary conditions and community participation with effects observed both across and within days. One interpretation suggests that secondary condition severity is tempered by adjusting participation. These results may have implications for intervening on these secondary conditions.
\end{abstract}

For most people, participation in daily life involves leaving home. People leave home to work, recreate, socialize, and shop, among other things. ${ }^{1}$ For people with disabilities, participation is a complex personal choice that is valued for many reasons. ${ }^{2}$ Secondary conditions like pain, fatigue and depression may limit people's engagement in activity outside the home. Existing studies of these secondary conditions have focused little attention on their impact on daily life. Thus, the impact of these secondary conditions on daily life remains largely unknown.
We address this gap in the literature. We obtained data from a mixed impairment sample using a longitudinal electronic diary technique known as Ecological Momentary Assessment (EMA). Using these data, we describe the relationship between pain, fatigue, depression and time spent at home. We examine these relationships both between subjects and within subjects over time.

Pain is a secondary condition associated with a variety of primary disabling conditions including spinal cord injury (SCI) ${ }^{3}$ multiple sclerosis (MS), ${ }^{4}$ arthritis, ${ }^{5}$ traumatic brain injury (TBI), ${ }^{6}$ amputation $^{7}$ and cerebral palsy. ${ }^{8}$ Self-report measures of pain interference among people with disabilities indicate that pain can affect social activities, recreation, 
mood, work, self-care, communication, learning new information/skills, and enjoyment of life. ${ }^{9,10}$ Not surprisingly, pain is associated with lower life satisfaction, poorer physical and mental health and level of handicap..$^{11,12}$

Fatigue is also a common secondary condition reported by people with MS ${ }^{13}$ stroke, ${ }^{14}$ arthritis, ${ }^{15}$ Parkinson's disease, ${ }^{16}$ TBI $^{17}$ and SCI ${ }^{18}$ It is associated with a reduction in daily activity engagement, including social and recreational activities, ${ }^{19-21}$ but may not be associated with engagement in major life activities like employment and education. ${ }^{22}$

Depression is a secondary condition that affects people diagnosed with diabetes related disability, ${ }^{23}$ Parkinson's' disease, ${ }^{24}$ epilepsy, ${ }^{25} \mathrm{SCI},{ }^{26} \mathrm{MS},{ }^{27}$ as well as those who have experienced a stroke. ${ }^{28}$ Endemic to depression is the effect it has on engaging in activity and, not surprisingly, depression is associated with a decrease in participation. ${ }^{23,29}$

When people make the decision to leave home, they consider the costs and the benefits of going out. For people experiencing pain, fatigue or depression the relative benefits and costs of leaving home may change. To go out, among other things (e.g., money), people need sufficient time, energy and motivation to engage in the planned activity. Pain, fatigue, or depression may decrease the resources available and make it more challenging to leave home. For instance, these conditions may increase the time and effort to complete self-care activities, and thus reduce the resources available to pursue activities outside the home. ${ }^{30}$ Alternatively, pain, fatigue, or depression may increase the "price" of activity outside the home. For instance, it may take more time and effort for someone with these conditions to complete the same activity. ${ }^{31}$ In either case, individuals experiencing greater pain, fatigue, or depression face more constraints to engaging in activities outside the home. ${ }^{32}$

Cross-sectional studies are inadequate for understanding the relationship between pain, fatigue, depression and community engagement. Standard between subjects analyses cannot rule out the possibility that unobserved characteristics drive observed correlations between pain, fatigue, or depression and one's propensity to remain home. Between subjects analyses also ignore within-person fluctuations in pain, fatigue, or depression. Within person fluctuations matter. They may drive an observed between subject relationship. Furthermore, they can illuminate whether people go home when they experience an increase in pain, fatigue, or depression. To develop the most effective interventions to increase community engagement, researchers need longitudinal data that is sensitive to daily fluctuations and individual differences.

Ecological Momentary Assessment (EMA), a technique subsumed under Experience Sampling Methodology, collects data in situ, which facilitates investigation of status fluctuations and individual differences. ${ }^{33,34}$ It typically uses electronic devices to collect data in the person's usual environment. It is a reliable and valid method for collecting data on a variety of variables (e.g., pain and emotional state) and reduces retrospective recall bias associated with autobiographic recall errors. ${ }^{34,35}$ The aim of the current study was to use EMA to explore the within-person temporal relationship between pain, fatigue, and depression on the amount of time people with impairments spend at home.

\section{Methods \\ Participants}

We recruited 525 participants in a small Western US city from an initial pool of 10,000 randomly selected households to complete a paper-and-pencil survey. Invitation letters and pre-coded, anonymous, postage paid post-cards were sent to each household. Interested participants who returned the post card and met inclusion criteria (i.e., endorsed one or more American Community Survey [ACS] questions $)^{36}$ were sent a survey using Dillman's procedures for materials development (e.g., cover letter content) and follow up. ${ }^{37}$ We recruited 149 of the survey respondents to complete the EMA by telephoning all individuals who gave permission on the survey to contact them for another study. The current study sample included 139 participants who responded to at least half of the 84 scheduled EMA prompts over the 14 day study period. Data were collected in 2013 and 2014.

Respondents included in the current analytic sample were between the ages of 19 and $75(M=55.7, S D=11.2)$ and were predominantly female (61.8\%), Caucasian (97.1\%), and college educated (73.3\% reported some college or more education). The majority were not employed (64.5\%) and reported median household income between $\$ 20,000$ and $\$ 30,000$ (Table 1).

\section{Measures}

We used the paper-and-pencil survey to collect a standard set of demographic variables including age, gender, income, employment status and educational attainment. We also collected the six American Community Survey (ACS) disability screener questions and the type of adaptive equipment respondents normally use.

We collected the EMA data using four-inch touch screen tablet computers (i.e., Samsung Galaxy Player 4.0) that were programmed to prompt participants using a random schedule within 2-h intervals (delivered between 9:00 am and 9:00 pm), six times daily, for 14 consecutive days. At each EMA prompt, participants reported where they were (e.g., at home), what they were doing (e.g., watching television), and questions about their experience in the moment (e.g., who they were with, how satisfied they were with the activity, their pain level). To indicate the level of pain they were experiencing, they used a 10-point rating scale anchored at each end $(0=$ No pain, $10=$ Pain as bad as you can imagine). Respondents used a five-point rating scale (i.e., $0=$ Not at all, $1=$ A little, $2=$ Somewhat, 
Table 1

Demographic characteristics of respondents $(n=139)$

\begin{tabular}{|c|c|c|}
\hline Variable & $n$ & $\%$ \\
\hline \multicolumn{3}{|l|}{ Gender } \\
\hline Male & 53 & 38.1 \\
\hline Female & 86 & 61.8 \\
\hline \multicolumn{3}{|l|}{ Ethnicity } \\
\hline White & 135 & 97.1 \\
\hline Non-white & 4 & 2.9 \\
\hline \multicolumn{3}{|l|}{ Relationship status } \\
\hline Married & 69 & 50.0 \\
\hline No longer married & 35 & 25.4 \\
\hline Never married & 18 & 13.0 \\
\hline Member of unmarried couple & 9 & 6.5 \\
\hline \multicolumn{3}{|l|}{ Education } \\
\hline Grade 12 or GED or less & 37 & 26.6 \\
\hline Some college or tech training or associate's & 58 & 41.7 \\
\hline Bachelor's degree or higher & 44 & 31.6 \\
\hline \multicolumn{3}{|l|}{ Income } \\
\hline$<\$ 10,000$ & 21 & 15.3 \\
\hline$\$ 10,001-40,000$ & 68 & 49.6 \\
\hline$\$ 40,001-80,000$ & 36 & 26.3 \\
\hline$\$ 80,001+$ & 12 & 8.8 \\
\hline \multicolumn{3}{|l|}{ Employment } \\
\hline Full-time $>30 \mathrm{~h} /$ week & 31 & 22.5 \\
\hline Part-time $1-30 \mathrm{~h} /$ week & 18 & 13.0 \\
\hline Not employed & 89 & 64.5 \\
\hline \multicolumn{3}{|l|}{ Volunteering } \\
\hline Weekly volunteer & 15 & 11.0 \\
\hline Occasional volunteer & 52 & 38.0 \\
\hline Does not volunteer & 70 & 51.0 \\
\hline \multicolumn{3}{|l|}{ Impairment } \\
\hline Deaf/hard of hearing & 23 & 16.5 \\
\hline Blind or difficulty seeing & 13 & 9.0 \\
\hline Concentration, memory, or decision making difficulty & 52 & 37.9 \\
\hline Difficulty walking or climbing stairs & 96 & 70.0 \\
\hline Difficulty dressing or bathing & 41 & 29.9 \\
\hline Difficulty running errands & 49 & 35.5 \\
\hline \multicolumn{3}{|l|}{ Equipment used } \\
\hline Needs physical assistance from others & 35 & 25.4 \\
\hline Uses a walker, cane, crutch, or brace & 36 & 26.1 \\
\hline Manual or power wheelchair users & 11 & 7.9 \\
\hline
\end{tabular}

$3=$ Quite a bit, $4=$ Very much) to indicate their current level of fatigue and depressed mood. Lastly, we obtained consent from 148 subjects to use the Global Positioning System (GPS) receiver for each EMA device to collect the geographic coordinates of the individual's location. ${ }^{38}$ This data was later used to validate the degree to which self-reported location matched GPS coordinates.

\section{Procedures}

All procedures were reviewed and approved by the Institutional Review Board at the University of Montana. Those recruited to complete the EMA attended a 90-min orientation where they provided informed consent for the study including opt-out consent for allowing the GPS receiver of the device to be activated. Then, we instructed participants on how to interpret each question and available responses, and how to enter their responses on the EMA device. We also gave each participant a training guidebook they could take home and refer to later.

For people with visual impairments, we offered a larger format device (i.e., Samsung Galaxy Tab 7.0 seven-inch tablet); all participants chose the smaller device and used personal magnifiers to view content. The sample did not include any participants who were totally blind. For individuals with dexterity problems, who might have had difficulty responding to a touch screen, we offered a stylus and/ or the larger format device. All of these participants chose to use a stylus and the smaller device.

\section{Data handling and analytic strategy}

We entered all survey data into a Microsoft Excel $^{39}$ spreadsheet programmed with input value constraints that did not allow out-of-range entries and checked the data input accuracy. We reviewed EMA data uploaded from the devices for accuracy and converted the raw data into Excel files. All data were imported into Stata ${ }^{40}$ for statistical analysis and standardized to improve interpretability for variables with different scales.

We divided our analysis into between subject and within subject analyses. For our between subjects analyses, we averaged individual EMA responses for all available measurement periods and combined them with demographic information obtained from the pre-EMA survey. We then examined descriptive statistics, correlations, and linear regression results. In our between subject regression analysis, we regressed the share of observations at home (measured as a standardized score) on standardized scores for a subjects' average pain, fatigue, and depressed mood (across the 14-day EMA measurement window) controlling for sex, age, ethnicity, and education. Confidence intervals for this regression were computed using heteroskedasticrobust standard errors.

For our within subject analyses, we examined the relationship between lagged (i.e., self-reported symptoms preceding subsequent "at home" observations) individual reports of pain, fatigue, and depressed mood and the likelihood that an individual is at home. We estimated these relationships using logistic regression with individual fixed effects and controlled for time of day (dummy variables for each of the 6 measurement periods $-2 \mathrm{~h}$ blocks between 9 am and $9 \mathrm{pm}$ - each day) and day of the week (a dummy variable equal to one if the measurement period occurred on a weekend). We explored both across and within day lags. For across day lags, we used the average of all available measurements from the previous day and regressed this mean on the probability of being at home today. For within day lags, we examined whether withinday lags were associated with participants being at home during any given time period that could be evaluated given the lag structure. For example, a one period lag within the day could be evaluated with five time periods, while a three period lag could only be evaluated with the three periods. 


\section{Results}

Overall, respondents completed $87 \%$ of the 84 possible study prompts. They reported that they were at home for $70 \%$ of those prompts. The Spearman rank order correlation between subjects "at home" response to the EMA question "Where are you?" and the GPS coordinate variable we constructed was $0.92(p<0.01)$. We used the subject's EMA response as the dependent variable in these analyses because there were some obvious anomalies in the GPS location coordinates (e.g., coordinates in uninhabited areas). ${ }^{a}$ With regard to the independent variables, the average raw scale pain rating across all observations was $3.86\left(\mathrm{SD}_{\text {Between }}=2.08\right.$; $\mathrm{SD}_{\mathrm{Within}}=1.38$ ), average depression was 1.73 $\left(\mathrm{SD}_{\text {Between }}=0.90 ; \mathrm{SD}_{\mathrm{Within}}=0.56\right)$ and average fatigue was $2.54\left(\mathrm{SD}_{\text {Between }}=0.84 ; \mathrm{SD}_{\text {Within }}=0.80\right)$.

The distribution of locations reported by total observations across all respondents and by the number of respondents is included in Table 2. Additionally, we examined the extent to which people reported electronic or computer based activity at home, which could affect interpretation of results. Of 596 observations of socializing, 343 were at home which included 191 instances of talking on the phone $(n=77), 46$ instances of social networking $(n=16)$ and 30 instances of other electronic communication $(n=15)$. Additionally, there were 388 instances of computer use for activities such as gaming or shopping $(n=74)$. Combined, these social and computer based activities at home accounted for $10 \%$ of the total observations at home.

At the between subject level (i.e., measured EMA responses averaged over 84 measurement periods), the correlations between the proportion of time respondents spent at home and their level of pain $(r=0.19)$, fatigue $(r=0.05)$ and depressed mood $(r=0.17)$ were statistically significant $(p<0.05)$ for pain and depressed mood. Taken together and regressed on the proportion of time spent at home, after adjusting for basic demographic variables, average pain and depressed mood were both positively associated with the proportion of time individuals reported being home, while fatigue was not positively associated with the proportion of time individuals reported being at home (Table 3).

Next, we examined the effects of within subject changes in pain, fatigue and depressed mood on the likelihood of being home within and across days, after accounting for variability due to time periods within the same day (i.e., time periods 1-6) and weekend versus weekday activity (Tables 4-6).

\section{Pain}

Table 4 includes the effect of changes in pain level on the likelihood the individual is at home. This table shows

\footnotetext{
a We programmed devices to use the coordinates of a WIFI signal if a GPS satellite lock was unavailable (i.e., when the device was in a large building with no windows). Location anomalies were associated with the WIFI location coordinates.
}

Table 2

Frequency of observations by location

\begin{tabular}{lcr}
\hline Location & Frequency $(\%)$ & $n(\%)$ \\
\hline Business or store & $615(6)$ & $123(88)$ \\
Church or religious place & $80(<1)$ & $33(24)$ \\
Gym or exercise facility & $84(<1)$ & $39(28)$ \\
Health care facility & $168(2)$ & $59(42)$ \\
Home & $7132(70)$ & $139(100)$ \\
Office building & $274(3)$ & $48(35)$ \\
Outside & $733(7)$ & $110(79)$ \\
Restaurant or bar & $145(1)$ & $63(45)$ \\
School or education & $188(2)$ & $31(22)$ \\
Someone else's home & $259(3)$ & $65(47)$ \\
Transportation vehicle & $371(4)$ & $96(69)$ \\
Venue such as a theater & $34(<1)$ & $18(13)$ \\
Other location & $126(1)$ & $49(35)$ \\
\hline
\end{tabular}

Frequency is the total number of observations in each location.

$n=$ the number of individuals with at least one observation in each location.

that individuals who experienced more pain yesterday or more pain earlier in the day (up to $6 \mathrm{~h}$ prior) are more likely to be at home in the current period. Specifically, for a one standard deviation unit increase in average pain yesterday, the odds that an individual is at home increases by an average of $36 \%$. A one standard-unit increase in pain three periods earlier in the day increases the odds that an individual is at home currently by $18 \%$, on average. Lastly, withinperiod pain results indicate that individuals reporting current pain are $24 \%$ less likely to be at home.

\section{Fatigue}

Results for fatigue are different (Table 5). There were no observed effects of fatigue on the likelihood of being at home measured within the period, or lagged one day. However, for a one standard-unit increase in fatigue one period prior, the odds of being home in the current period increased by $14 \%$.

Table 3

Linear regression of between subject predictors for the proportion of time spent at home

\begin{tabular}{lccr}
\hline \multicolumn{3}{c}{ Proportion of time at home } \\
\cline { 2 - 4 } Variables & $\beta$ & $p$ & $95 \%$ CI \\
\hline Constant & -0.58 & 0.69 & $-1.82,0.65$ \\
Age & 0.01 & 0.24 & $-0.01,0.03$ \\
Gender & 0.03 & 0.86 & $-0.32,0.38$ \\
Caucasian & 0.15 & 0.68 & $-0.58,0.88$ \\
Some college & -0.16 & 0.38 & $-0.54,0.21$ \\
College & -0.35 & 0.13 & $-0.79,0.10$ \\
Average pain & $0.19 *$ & 0.04 & $0.01,0.37$ \\
Average fatigue & -0.14 & 0.29 & $-0.39,0.12$ \\
Average depression & $0.22^{*}$ & 0.03 & $0.02,0.42$ \\
$R^{2}$ & 0.10 & & \\
\hline
\end{tabular}

Variables entered represent average values across all 84 EMA measurement periods. Gender is coded 1 for women, 0 for men; Caucasian is coded 1, Caucasian 1, other ethnicities 0; Some College and College variables are in reference to high school education or less.

$* p<0.05$. 
Table 4

Pain measured contemporaneously, lagged one day, and lagged between periods within days regressed on being at home

\begin{tabular}{lll} 
& \multicolumn{2}{l}{ At home } \\
\cline { 2 - 3 } Pain & OR & $95 \%$ CI \\
\hline Current pain & $0.76^{* * *}$ & $0.61-0.93$ \\
Mean pain yesterday & $1.36^{* *}$ & $1.08-1.72$ \\
Pain lagged 3 periods & $1.18^{\mathrm{a}}$ & $1.01-1.38$ \\
Time period 4 (ref.) & 1 & \\
Time period 5 & $1.77^{\mathrm{b} * *}$ & $1.40-2.23$ \\
Time period 6 & $3.32^{* * *}$ & $2.34-4.07$ \\
Weekend & 1.10 & $0.87-1.40$ \\
\hline
\end{tabular}

Time period variables represent measurement periods within the day. Weekend is a binary weekday (coded 0 ), weekend day (coded 1) variable. Values presented here represent standardized coefficients.

$* p<0.05 ; * * p<0.01 ; * * *<0.001$.

${ }^{a}$ Only home status at periods 4,5 , and 6 were covaried given the effect of within day pain lagged up to 3 periods.

b Time periods 5 and 6 were entered as covariates (time period 4 reference) to account for within day activity and to isolate the effects of contemporaneous pain, pain lagged one day and pain within the day.

\section{Depressed mood}

As with fatigue, there was no effect of within-period depressed mood on the likelihood of being at home in the current period (Table 6). However, results indicate that average depressed mood scores yesterday, and one measurement period prior (up to $2 \mathrm{~h}$ ) were related to the odds of being at home in the current period. On average, individuals who reported a one standard-unit increase in average depressed mood yesterday were $28 \%$ more likely to report being at home in the current period. On the other hand, for a one standard-unit increase in depressed mood one period prior, individuals were $15 \%$ less likely to report being at home. These results suggest that individuals who experience increases in average prior-day depressed mood tend to spend more time at home the following day, but are less

Table 5

Fatigue measured contemporaneously, lagged one day, and lagged between periods within days regressed on being at home

\begin{tabular}{lll}
\hline & At home \\
\cline { 2 - 3 } Fatigue & OR & $95 \%$ CI \\
\hline Current fatigue & 0.92 & $0.82-1.03$ \\
Mean fatigue yesterday & 1.11 & $0.94-1.31$ \\
Fatigue lagged 1 period & $1.14^{* *}$ & $1.03-1.27$ \\
Time period 2 (ref.) & 1 & \\
Time period 3 & 0.92 & $0.76-1.10$ \\
Time period 4 & 1.23 & $0.97-1.56$ \\
Time period 5 & $2.20^{* * *}$ & $1.68-2.89$ \\
Time period 6 & $3.98^{* * *}$ & $2.82-5.61$ \\
Weekend & $1.26^{*}$ & $1.02-1.55$ \\
\hline
\end{tabular}

Time Period variables represent measurement periods within the day. Weekend is a binary weekday (coded 0 ), weekend day (coded 1) variable. Values presented here represent standardized coefficients.

$* p<0.05 ; * * p<0.01 ; * * * p<0.001$.

a Time periods 3 through 6 are accounted for (period 2 reference) to observe the effects of contemporaneous fatigue, and fatigue lagged one day, and fatigue lagged one period prior.
Table 6

Depression measured contemporaneously, lagged one day, and lagged between periods within days regressed on being at home

\begin{tabular}{lll}
\hline & At home \\
\cline { 2 - 3 } Depression & OR & $95 \%$ CI \\
\hline Current depressed mood & 1.10 & $0.93-1.32$ \\
Mean depressed mood yesterday & $1.28^{*}$ & $1.02-1.62$ \\
Depressed mood lagged 1 period & $0.85^{*}$ & $0.73-0.99$ \\
Time period 2 (ref.) & 1 & \\
Time period 3 & 0.93 & $0.78-1.11$ \\
Time period 4 & $1.26^{*}$ & $1.00-1.59$ \\
Time period 5 & $2.32^{* * *}$ & $1.78-3.02$ \\
Time period 6 & $4.15^{* * *}$ & $2.99-5.77$ \\
Weekend & $1.24^{*}$ & $1.01-1.53$ \\
\hline
\end{tabular}

Time Period variables represent measurement periods within the day. Weekend is a binary weekday (coded 0 ), weekend day (coded 1) variable. Values presented here represent standardized coefficients.

$* p<0.05 ; * * * p<0.001$

a Time periods 3 through 6 are accounted for (period 2 reference) to observe the effects of contemporaneous fatigue, and fatigue lagged one day, and fatigue lagged one period prior.

likely to remain home if their depressed mood increases within a given day.

\section{Discussion}

We used EMA to explore the temporal association between pain, fatigue, and depressed mood on both the amount of time people spent at home and on the likelihood that people were at home at any given time during the study. Between subject differences in the proportion of time people spent at home over the course of the study were observed only for pain and depressed mood. Within subject results showed that pain and depressed mood were associated with the likelihood that an individual was at home both across and within days. Fatigue was only related to the likelihood of being home within a day. These results are consistent with prior research that has linked higher levels of pain and fatigue to lower activity levels. Higher levels of activity following higher levels of depressed mood within the day were contrary to our expectations. These results highlight the ecological fallacy of using between subject results to infer within subject effects. ${ }^{41}$

The between subject results for pain and depressed mood were consistent with those reported in cross-sectional research, with higher average pain and depressed mood associated with a greater proportion of time spent at home. For example, pain interferes with the activities of people with MS and SCI. ${ }^{9,10}$ However, for this sample there was not an association between fatigue and the proportion of time spent at home. One possibility for this difference may be that while fatigue may affect the quality of participation, it has a smaller effect on the quantity as indicated by cross-sectional modeling. Alternatively, there may be opposing effects such that people with higher fatigue are 
either more likely to stay home or people who are more active report more fatigue, but are less likely to be home.

Within subject effects are evident for all three variables. Depressed mood and pain have effects across days. This may reflect the fact that interventions and selfmanagement strategies for these conditions experienced by our sample have limited short-term effects when compared with the effect that resting or sleep have on reducing fatigue. Within days, people have less pain when they are at home; however, increases in pain during the early part of a day increases the likelihood that an individual is at home later in the day. These results suggest that when people notice an increase in pain they go home (or remain home). Fatigue shows a similar pattern within the day - people report lower fatigue at home and increases in fatigue earlier in the day are associated with being at home later in the day. For these data, fatigue has an immediate effect with the likelihood of being home, evident within the next $2 \mathrm{~h}$, while pain has both an immediate and lagged effect with the likelihood of being home, which is evident for as long as $6 \mathrm{~h}$ later. This indicates that pain affects being home over a longer period than fatigue, which could reflect that rest improves fatigue, which reduces its longer-term effects on being home (e.g., after resting, people may go out again).

In contrast to pain and fatigue, we observed a different within day-effect for depressed mood. Increases in depressed mood ratings within the day were associated with decreased probability that individuals would be home one period later. This could reflect a self-management strategy used by respondents, wherein perceived increases in depressed mood prompt going out to help manage mood. This would be consistent with behavioral activation treatment ${ }^{42}$ for depression that has shown that mood improves when activity levels increase. ${ }^{43}$ Another interpretation might be that depression scores increase in anticipation of planned or scheduled activities outside the home.

These results may reflect the tension that people experience between being out in the community and managing their pain, fatigue and depressed mood. On the one hand, increase in depressed mood is associated with getting out of the house within the next few hours; on the other hand, being out increases pain and fatigue. ${ }^{29,44}$ This may set up a dysfunctional cycle of symptom management that ultimately has the potential to decrease community engagement. Alternatively, because pain and fatigue may be reduced over time through exercise and physical activity that increases physical capacity, these results suggest that any subsequent increase in activity may help people manage depressed mood. ${ }^{45}$ Lastly, if these results reflect depression self-management, then they may reflect the importance of increasing physical capacity that supports community engagement without increasing pain and fatigue.

Daily activity in the community comes at a price and sooner or later, everyone goes home. Time spent away from home may be understood along a continuum based on opportunity, preference, and constraint parameters. At one end, total lack of opportunity to access the community is associated with spending no time away from home. However, with opportunity comes choice, which is governed by preferences and constraints. For people with disabilities and associated secondary conditions, preferences may be shaped by available opportunities and constraints that exert a greater influence on their choices than those without disabilities. In this framework, pain and fatigue are constraints on community engagement that may increase risk for depressed mood. Research on symptom clustering has suggested that pain, fatigue and depression move together when examined with cross-sectional data. ${ }^{46,47}$ The results of this study may reflect the balance people work to achieve between pain, fatigue, depression and community engagement.

\section{Limitations}

There are a number of limitations to interpreting these results. First, the study sample was limited in geographic coverage and not demographically representative of the US population of people with disability, which limits the generalizability of these results. Further, without a comparison sample of people without disability, we do not know if these results are specific to people with disabilities or would also be observed in the general population. Second, while use of EMA may reduce recall error, repeated measures may prompt instrumentation effects. For example, rating secondary conditions six times a day may have increased secondary condition salience for respondents, which may have prompted behavior (e.g., raised awareness of depressed mood prompting people to leave home). We examined the data for these effects and while we found a slight increase in the value of pain ratings over the course of the study $(\mathrm{ETA}=0.14, p<0.01$ ), we did not find any evidence of trends in either fatigue or depression. Some participants made anecdotal comments that rating their pain helped them understand its effects on their daily life, an observation that is consistent with instrumentation effects. Third, the lagged structure of the data analytic approach is a limitation. While useful for examining associations over time, the lagged structure limits our ability to model both the sequential effects of secondary conditions on each other and on being at home simultaneously given the sample size of this study. Consequently we chose to analyze pain, fatigue, and depression as predictors independently. Missing data represents another potential source of bias in this study. If the pattern of missing data is related to the temporal pattern observed in the independent variables, this artifact could account for these results. We examined the data for these patterns but did not find evidence of this effect. Fourth, in retrospect, the omission of an EMA variable about pain medication use is another study limitation. These results may reflect both analgesic and fatigue associated with pain medication use. Finally, while our results suggest that relationships exist between pain, fatigue, 
depression and one's propensity to be at home, the variation in secondary conditions used to estimate our results is not strictly exogenous and therefore our analysis may suffer from some degree of endogeneity or omitted variable bias (e.g., pain medication use).

Modern technology that allows researchers to collect EMA data is now ubiquitous in much of the world. Future research may capitalize on these measurement techniques to extend participation research that will allow investigators to examine with much greater resolution personal and environmental factors that affect participation (Livingston et al, 2015). For example, with more subjects, this line of research could begin to model the temporal effects of these secondary conditions on each other and on participation to understand better sequential effects of secondary conditions on participation. Alternatively, future research could examine how specific activities (e.g., visiting friends, shopping alone, doing volunteer work) affect secondary conditions and participation. Lastly, future studies may use EMA to evaluate interventions (e.g., ecological momentary interventions) to increase community participation and to examine the sequential effects of these secondary conditions as people make choices to increase their involvement in their community.

\section{Conclusion}

Leaving home is important to living a full life and an important aspect of community engagement. Results from this study indicate that secondary conditions play an important role in that choice. Even more, these results suggest there may be opposing effects of community participation on secondary conditions. Individuals may leave home to manage depressed mood, but return home when pain and fatigue increase. As such, this study suggests that the most effective interventions may address a symptom cluster of pain, fatigue and depression.

\section{Acknowledgments}

The authors would like to thank our research advisors David Gray, Mark Jensen, Mike Mayer and Glen White for their invaluable contributions to the development of project materials and procedures. We also acknowledge the contributions of Lillie Greiman and research assistants Lorraine Adams, Seterra Burleson, Cathy Berendts, Alexandra Schiwal and Sandra Skogley, who contributed to data collection and management for the project.

\section{References}

1. Flood SM, Moen P. Healthy time use in the encore years: do work, resources, relations, and gender matter? J Health Soc Behav. 2015;56(1):74-97.
2. Hammel J, Magasi S, Heinemann A, Whiteneck G, Bogner J, Rodriguez E. What does participation mean? An insider perspective from people with disabilities. Disabil Rehabil. 2008;30(19): 1445-1460.

3. Saulino M. Spinal cord injury pain. Phys Med Rehabil Clin N Am. 2014;25(2):397-410.

4. Foley PL, Vesterinen HM, Laird BJ, et al. Prevalence and natural history of pain in adults with multiple sclerosis: systematic review and meta-analysis. Pain. 2013;154(5):632-642.

5. Jakobsson U, Hallberg IR. Pain and quality of life among older people with rheumatoid arthritis and/or osteoarthritis: a literature review. $J$ Clin Nurs. 2002;11(4):430-443.

6. Lucas S, Hoffman JM, Bell KR, Dikmen S. A prospective study of prevalence and characterization of headache following mild traumatic brain injury. Cephalalgia. 2014;34(2):93-102.

7. Nikolajsen L, Jensen TS. Phantom limb pain. $\mathrm{Br} J$ Anaesth. 2001;87(1):107-116.

8. Van Der Slot WM, Nieuwenhuijsen C, Van Den Berg-Emons RJ, et al. Chronic pain, fatigue, and depressive symptoms in adults with spastic bilateral cerebral palsy. Dev Med Child Neurol. 2012;54(9):836-842.

9. Raichle KA, Osborne TL, Jensen MP, Cardenas D. The reliability and validity of pain interference measures in persons with spinal cord injury. J Pain. 2006;7(3):179-186.

10. Osborne TL, Raichle KA, Jensen MP, Ehde DM, Kraft G. The reliability and validity of pain interference measures in persons with multiple sclerosis. J Pain Symptom Manage. 2006;32(3):217-229.

11. Putzke JD, Richards JS, Dowler RN. The impact of pain in spinal cord injury: a case-control study. Rehabil Psychol. 2000;45(4):386-401.

12. Osborne TL, Turner AP, Williams RM, et al. Correlates of pain interference in multiple sclerosis. Rehabil Psychol. 2006;51(2):166-174.

13. Induruwa I, Constantinescu CS, Gran B. Fatigue in multiple sclerosis-a brief review. J Neurol Sci. 2012;323(1):9-15.

14. Lerdal A, Bakken LN, Kouwenhoven SE, et al. Poststroke fatigue-a review. J Pain Symptom Manage. 2009;38(6):928-949.

15. Murphy SL, Smith DM, Clauw DJ, Alexander NB. The impact of momentary pain and fatigue on physical activity in women with osteoarthritis. Arthritis Care Res. 2008;59(6):849-856.

16. Friedman JH, Brown RG, Comella C, et al. Fatigue in Parkinson's disease: a review. Mov Disord. 2007;22(3):297-308.

17. Bushnik T, Englander J, Wright J. The experience of fatigue in the first 2 years after moderate-to-severe traumatic brain injury: a preliminary report. J Head Trauma Rehabil. 2008;23(1):17-24.

18. Craig A, Tran Y, Wijesuriya N, Middleton J. Fatigue and tiredness in people with spinal cord injury. J Psychosom Res. 2012;73(3): 205-210.

19. Michael KM, Allen JK, Macko RF. Fatigue after stroke: relationship to mobility, fitness, ambulatory activity, social support, and falls efficacy. Rehabil Nurs. 2006;31(5):210-217.

20. Flachenecker P, Kumpfel T, Kallmann B, et al. Fatigue in multiple sclerosis: a comparison of different rating scales and correlation to clinical parameters. Mult Scler. 2002;8(6):523-526.

21. Gagnon C, Mathieu J, Jean S, et al. Predictors of disrupted social participation in myotonic dystrophy type 1. Arch Phys Med Rehabil. 2008;89(7):1246-1255.

22. Cantor JB, Ashman T, Gordon W, et al. Fatigue after traumatic brain injury and its impact on participation and quality of life. J Head Trauma Rehabil. 2008;23(1):41-51.

23. Von Korff M, Katon W, Lin E, et al. Potentially modifiable factors associated with disability among people with diabetes. Psychosom Med. 2005;67(2):233-240.

24. Arun MP, Bharath S, Pal PK, Singh G. Relationship of depression, disability, and quality of life in Parkinson's disease: a hospital-based case-control study. Neurol India. 2011;59(2):185-189.

25. Fiest KM, Dykeman J, Patten SB, et al. Depression in epilepsy: a systematic review and meta-analysis. Neurology. 2013;80(6):590-599.

26. Saunders LL, Krause J, Focht K. A longitudinal study of depression in survivors of spinal cord injury. Spinal Cord. 2012;50(1):72-77. 
27. Chwastiak L, Ehde DM, Gibbons LE, Sullivan M, Bowen JD, Kraft GH. Depressive symptoms and severity of illness in multiple sclerosis: epidemiologic study of a large community sample. Am J Psychiatry; 2002:1862-1868.

28. Ayerbe L, Ayis S, Wolfe CD, Rudd AG. Natural history, predictors and outcomes of depression after stroke: systematic review and meta-analysis. Br J Psychiatry. 2013;202(1):14-21.

29. Wilkie R, Peat G, Thomas E, Croft P. Factors associated with participation restriction in community-dwelling adults aged 50 years and over. Qual Life Res. 2007;16(7):1147-1156.

30. Mitra S. The capability approach and disability. J Disabil Policy Stud. 2006;16(4):236-247.

31. World Health Organization. International Classification of Functioning, Disability, and Health. Geneva: World Health Organization; 2001

32. Knaggs JD, Larkin KA, Manini TM. Metabolic cost of daily activities and effect of mobility impairment in older adults. J Am Geriatr Soc. 2011;59(11):2118-2123.

33. Csikszentmihalyi M, Larson R, Prescott S. The ecology of adolescent activity and experience. J Youth Adolesc. 1977;6(3):281-294.

34. Stone AA, Shiffman S. Ecological momentary assessment (EMA) in behavorial medicine. Ann Behav Med. 1994;16(3):199-202.

35. Piasecki TM, Hufford MR, Solhan M, Trull TJ. Assessing clients in their natural environments with electronic diaries: rationale, benefits, limitations, and barriers. Psychol Assess. 2007;19(1):25-43.

36. United States Census Bureau. American Community Survey S1801. Disability Characteristics, http://factfinder.census.gov/servlet/STTable? _bm =y\&-qr_name=ACS_2005_EST_G00_S1801\&-geo_id=01000US \&-ds_name $=$ ACS_2005_EST_G00_\&-_lang $=$ en $\&$-format $=\&-C O N T$ $\mathrm{EXT}=\mathrm{st} ; 2005$. Accessed 19.05.08.

37. Dillman D. Mail and Internet Surveys. The Tailored Design Method. 2nd ed. New Jersey: John Wiley \& Sons, Inc; 2007.

38. Google I. Configure access points with Google location feature. Updated 2015. https://support.google.com/nexus/answer/1725632?hl=en; Accessed 29.05.15.

39. Microsoft. Microsoft Excel. Microsoft Corporation; 2013.

40. StataCorp. Stata Statistical Software: Release 14; 2015.

41. Monaco J. Ecological Fallacy. Encyclopedia of Behavioral Medicine; 2013:644.

42. Hopko DR, Lejuez C, Ruggiero KJ, Eifert GH. Contemporary behavioral activation treatments for depression: procedures, principles, and progress. Clin Psychol Rev. 2003;23(5):699-717.

43. Jacobson NS, Dobson KS, Truax PA, et al. A component analysis of cognitive-behavioral treatment for depression. J Consult Clin Psychol. 1996;64(2):295.

44. Malone LA, Vogtle LK. Pain and fatigue consistency in adults with cerebral palsy. Disabil Rehabil. 2010;32(5):385-391.

45. Rimmer JH, Chen M, McCubbin JA, Drum C, Peterson J. Exercise intervention research on persons with disabilities: what we know and where we need to go. Am J Phys Med Rehabil. March 01, 2010;89(3):249-263.

46. Motl RW, Suh Y, Weikert M. Symptom cluster and quality of life in multiple sclerosis. J Pain Symptom Manage. 2010;39(6):1025-1032.

47. Ravesloot C, Seekins T, Walsh J. A structural analysis of secondary conditions experienced by people with physical disabilities. Rehabil Psychol. 1997;42(1):3-16.

Preliminary results were presented at the Association of Programs for Rural Independent Living annual meeting. Albuquerque, NM 2014.

Disclosures: The contents of this paper were developed under a grant from the Department of Education, NIDRR grant number H133G110077 awarded to Craig Ravesloot and Catherine Ipsen. However, those do not necessarily represent the policy of the Department of Education, and readers should not assume endorsement by the Federal Government. 